\title{
Promoting Gratitude as a Resource for Sustainable Mental Health: Results of a 3-Armed Randomized Controlled Trial up to 6 Months Follow-up
}

\author{
Ernst T. Bohlmeijer ${ }^{1} \cdot$ Jannis T. Kraiss ${ }^{1} \cdot$ Philip Watkins $^{2} \cdot$ Marijke Schotanus-Dijkstra $^{1}$
}

Published online: 7 May 2020

(c) The Author(s) 2020

\begin{abstract}
The aim of the current study was to evaluate the impact of a 6-week gratitude intervention for people with low to moderate well-being and moderate symptomatology of depression and anxiety up to 6 months follow-up. 217 Dutch adults were randomly assigned to one of three conditions: a 6-week gratitude intervention, a 6-week self-kindness intervention as an active control condition and a waitlist control condition. Participants completed online assessments on well-being, depression, anxiety and gratitude at baseline, post-test, 6 weeks and 6 months follow-up. Changes in outcome measures over time were examined using multilevel growth curve modeling in $\mathrm{R}$ to account for repeated measures nested within individuals. The gratitude intervention was more effective in improving mental well-being in comparison to the self-kindness intervention $(d=.63$ at post-intervention and $d=.40$ at 6 weeks follow-up) and waitlist control ( $d=.93$ at post-intervention and $d=.66$ at 6 weeks follow-up). The data also demonstrated that the gratitude intervention was superior to waitlist control and practicing self-kindness on various measures of gratitude but not on distress. The results of this study suggest that a 6-week gratitude intervention is an effective, low-intensity intervention for enhancing mental well-being but not distress among people with low to moderate levels of well-being and moderate distress, at least in higher-educated women. The sustained effects on various measures of gratitude up to 6 months follow-up suggest that it is possible to promote a lasting appreciative perspective on life.
\end{abstract}

Keywords Gratitude $\cdot$ Low-intensity intervention · Positive psychology $\cdot$ Randomized controlled trial $\cdot$ Well-being

Ernst T. Bohlmeijer

e.t.bohlmeijer@utwente.nl

Marijke Schotanus-Dijkstra

m.schotanus@utwente.nl

1 Centre for eHealth and Well-Being Research, Department of Psychology, Health and Technology,

University of Twente, P.O. Box 217, 7500 AE Enschede, The Netherlands

2 Department of Psychology, Eastern Washington University, Cheney, WA, USA 


\section{Introduction}

Traditionally, mental health care is primarily associated with reducing distress and psychopathology. However mental health is more than the absence of mental illness and comprises emotional, social and psychological well-being as well (e.g. Keyes 2005; Lamers et al. 2011; Westerhof and Keyes 2010). There is growing evidence that the absence of mental illness does not necessarily imply the presence of mental well-being and that the presence of mental illness does not necessarily exclude mental well-being or flourishing (Keyes 2005; Lamers et al. 2011; Westerhof and Keyes 2010; de Vos et al. 2018; Franken et al. 2018; Schotanus-Dijkstra et al. 2019b). Mental well-being is a relevant outcome in public health as it reduces the risk of the incidence of mental illnesses (Schotanus-Dijkstra et al. 2017; Lamers et al. 2015; Keyes et al. 2010; Grant et al. 2013; Wood and Joseph 2010).

The high prevalence of common mental disorders in the general population (e.g. Whiteford et al. 2013) and the fact that most people experience impaired levels of well-being (Schotanus-Dijkstra et al. 2016) underscore the need for large-scale, low-intensity interventions that promote and sustain mental health (e.g. Isaacowitz et al. 2003; Cloninger 2006; Huppert 2004; Schotanus-Dijkstra et al. 2019a; Fledderus et al. 2012). Gratitude may be one such intervention. Gratitude has been defined as both a positive affect resulting from the perception of receiving a benefit from another person (McCullough et al. 2002) and a trait, which includes the ability to appreciate simple things in life, sense of abundance and experience and express gratitude towards others (Watkins et al. 2003; Wood et al. 2009). A growing number of longitudinal studies have demonstrated the positive relation between gratitude and mental health (Wood et al. 2010). For example, it has been found that higher levels of gratitude predicts improvements in well-being and distress over time for various populations such as healthy adults (Disabato et al. 2016), heart patients (Millstein et al. 2016), people with rheumatic disorders (Sirois and Wood 2017) and war veterans (Kashdan et al. 2006).

In a recent meta-analysis of gratitude interventions such as the gratitude letter and gratitude list, Davis et al. (2016) found limited and inconclusive evidence for their efficacy. Reviews and meta-analyses (Davis et al. 2016; Dickens 2017; Wood et al. 2010) identified some factors that may explain the so-far limited impact of gratitude interventions and recommended to address these limitations in future trials. First, the majority of studies included predominantly healthy populations with higher levels of well-being and gratitude, limiting the potential for change. Secondly, most studies evaluated single interventions of short duration (one or two weeks). Increasing the dosage and variation of gratitude interventions may contribute to larger effects on mental health (Lyubomirsky and Layous 2013). Thirdly, there is a scarcity of longer follow-up measurements, and thereby a lack of knowledge about the maintenance of effects of gratitude interventions on mental health. And fourth, there is a need for outcome instruments measuring more proximal effects of gratitude interventions such as gratitude as a mood.

In order to address these gaps in gratitude intervention research, a 3-armed trial was conducted. The aim of the present study was to assess the effects of a 6-week gratitude intervention on mental health and on various measures of gratitude up to 6 months followup in an adult sample with low to moderate levels of well-being and moderate levels of distress. We hypothesized that the gratitude intervention would be superior in comparison to active and waitlist control in improving well-being, decreasing depression and anxiety and promoting gratitude. 


\section{Method}

\subsection{Design}

The current paper describes results from three of the four conditions of a large parallel, randomized controlled trial in the Netherlands about the efficacy of different happiness exercises. ${ }^{1}$ Practicing various gratitude exercises during 6 weeks was compared with performing self-kindness acts during 6 weeks (active control group) and waiting for performing a well-being intervention-exercise (waitlist control group). Participants completed online assessments at baseline (T0), post-test (T1), 6 weeks follow-up (T2) and 6 months followup (T3). A power analysis showed that 78 participants per condition were needed to obtain an effect size of at least $d=.45$ on well-being (Davis et al. 2016; Kerr et al. 2015) assuming a two-tailed test with alpha of .05 and a power of $.80(1-\beta)$. This study was approved by the Ethics Committee of the University of Twente (BCE17240) and registered in the Dutch Trial Register (NTR6786).

\subsection{Participants and Procedure}

In September 2017, advertisements were placed via different media, recruiting participants via Facebook/LinkedIn $(n=425)$, a popular psychology magazine $(n=156)$ and national and regional newspapers $(n=72)$. The recruitment message was: 'Can your well-being use a boost? Join this study on the effects of happiness exercises from the University of Twente for free'. Participants needed to be at least 18 years old, have a sufficient Internet connection and a valid email address, and they had to master the Dutch language to complete questionnaires and follow the intervention instructions. Interested participants applied online for the study. Participants who completed the online informed consent procedure were automatically redirected to an online screening questionnaire. Eligible participants had no severe depressive or anxiety symptoms, indicated by a score $<34$ on the Center for Epidemiological Studies Depression (CES-D) questionnaire (Bouma et al. 1995; Santor et al. 1995; Radloff 1977) and a score < 15 on the Generalized Anxiety Disorder-7 (GAD7) questionnaire (Donker et al. 2009; Spitzer et al. 2006). For the current study, people who were already flourishing $(n=37)$, as measured with the Mental Health Continuum-Short Form (Keyes et al. 2008; Lamers et al. 2011), were excluded to create a more homogeneous group. Analyses including the people who were flourishing at baseline showed similar results as presented here. After completing the baseline survey, participants were randomly assigned to each condition using random numbers from randomizer.org. Randomization was stratified by gender, education level (low, intermediate, high) and flourishing (possess at least one of the three aspects of emotional well-being and at least six of the eleven aspects of social and psychological well-being) to ensure equal distribution of these characteristics among the conditions.

The final sample consisted of 217 participants with an allocation ratio of $1: 1: 1$. The mean age of the participants was 48.6 years $(\mathrm{SD}=9.6)$, with a range between 18 and

\footnotetext{
1 Two other conditions were two variants of performing acts of kindness for others, of which the results in comparison with control is described elsewhere (Nelson et al. Submitted). We choose to use the budget for advertisement efficiently, and therefore recruited participants for two studies simultaneously (i.e. gratitude versus control; acts of kindness versus control).
} 
Table 1 Baseline characteristics of the participants practicing gratitude, practicing self-kindness, or who were waiting for a well-being exercise

\begin{tabular}{lccc}
\hline & $\begin{array}{l}\text { Gratitude-intervention } \\
(n=73)\end{array}$ & $\begin{array}{l}\text { Active control } \\
(n=73)\end{array}$ & $\begin{array}{l}\text { Waitlist control } \\
(n=71)\end{array}$ \\
\hline Age, $M(S D)$ & $47.4(9.7)$ & $48.4(9.9)$ & $50.01(9.2)$ \\
Female gender, $n(\%)$ & $65(89.0)$ & $66(90.4)$ & $64(90.1)$ \\
Education, $n(\%)$ & $2(2.7)$ & $3(4.1)$ & $3(4.2)$ \\
Low & $14(19.2)$ & $13(17.8)$ & $12(16.9)$ \\
Intermediate & $57(78.1)$ & $57(78.1)$ & $56(78.9)$ \\
High & & $34(46.6)$ & $35(49.3)$ \\
Marital status, $n(\%)$ & $18(24.7)$ & $18(25.4)$ \\
Married & $16(21.9)$ & $21(28.8)$ & $18(25.4)$ \\
Divorced or widowed & $60(82.2)$ & $68(95.8)$ \\
Never been married & $20(27.4)$ & $23(31.5)$ & $20(28.2)$ \\
Dutch nationality, $n(\%)$ & $64(87.7)$ & $38(52.1)$ & $27(38.0)$ \\
Living alone, $n(\%)$ & $13(17.8)$ & $59(80.8)$ & $50(70.4)$ \\
Living with children, $n(\%)$ & $41(56.2)$ & & \\
Paid employment, $n(\%)$ & $51(69.9)$ & & \\
\hline
\end{tabular}

67 years. Participants were mainly female (89.9\%), higher educated (78.3\%), of Dutch nationality $(88.5 \%)$, married $(48.8 \%)$, living with others $(74.2 \%)$ and in paid employment $(73.7 \%)$. Socio-demographic characteristics did not significantly differ between groups, except for Dutch nationality which was more pronounced in the waitlist condition compared to the other conditions, $\chi^{2}(2)=6.59, p=.037$. Also, a marginal difference was found for living with children showing that fewer participants in the waitlist condition were living with children compared to the other conditions, $\chi^{2}(2)=5.19, p=.075$ (Table 1). Intervention instructions were sent to the participants on each Sunday, during 6 weeks. If necessary, reminders were sent to increase adherence. At the T3 assessment, participants were informed that they could win one of 20 books about gratitude if they completed that last survey.

\subsection{Conditions}

The 6 weeks gratitude intervention consisted of evidence-based gratitude exercises which were mainly writing exercises (Emmons and McCullough 2003; Emmons and Stern 2013), psycho-education (e.g. There are two types of gratitude; (1) more general appreciation such as for your living standards, talents or possessions, and (2) appreciation for others, such as about how friendly or supporting others have been for you.) and questions that trigger reflection about cultivating gratitude (e.g. What did you feel when practicing the gratitude exercise of this week? What did it mean for your daily activities?). The weekly gratitude exercises and general instructions are displayed in Table 2. On average, we expected that participants would invest around 15 min a day on 5 days per week (75 min per week).

Participants in the active control condition received the same instructions each week for 6 weeks in total. They were instructed to perform five self-kindness activities on one day per week: 'In our daily lives, we all perform acts of kindness for others, but we often 


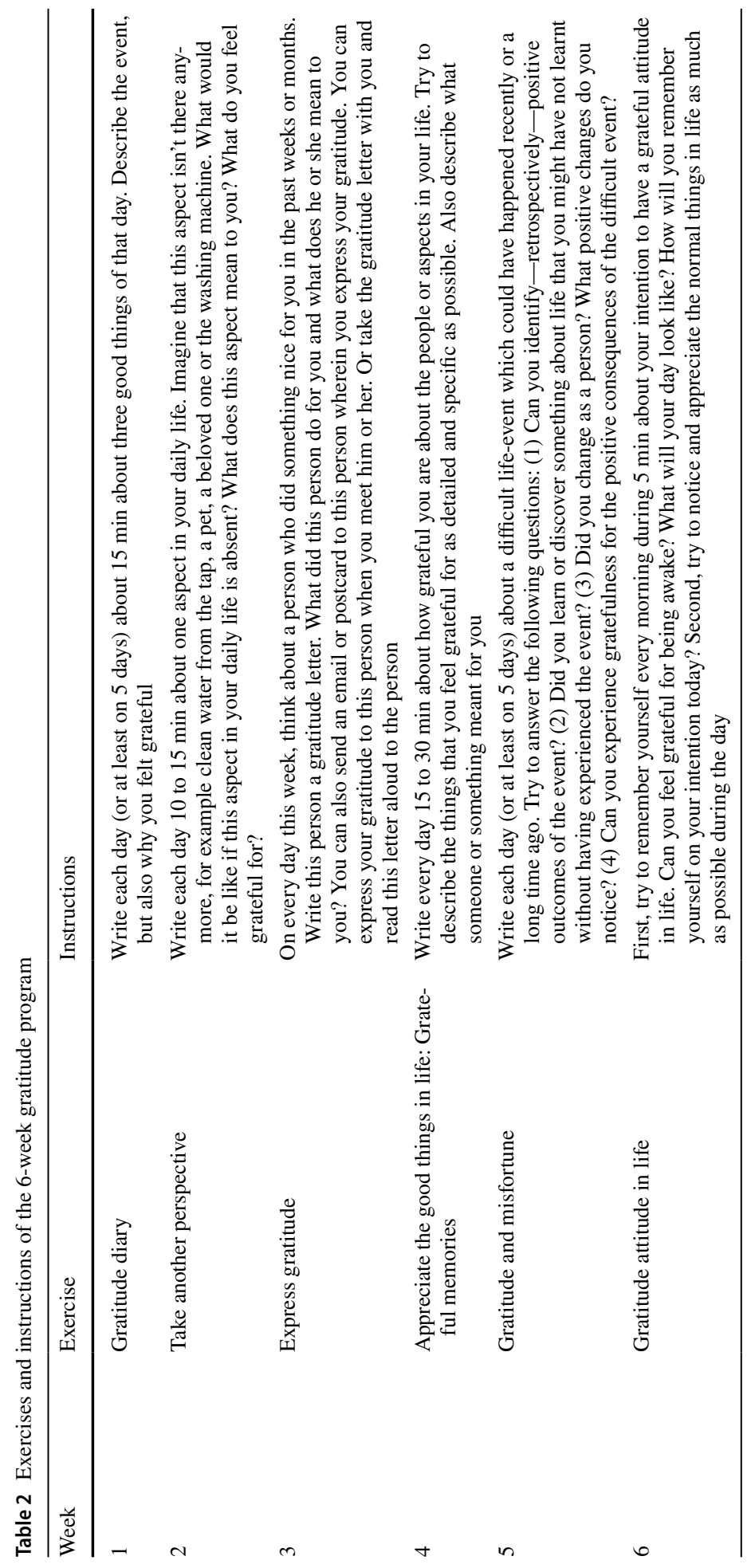


neglect to do nice things for ourselves - small and simple things that require relatively little extra money or effort. Examples include treating yourself on a special coffee or on your favorite pastry, magazine or meal, taking a 5-min break from work or study, give yourself a compliment or go for a walk. Now and then, you can treat yourself on something bigger, such as a massage or spending time on your favorite hobby. Within the next five days, you pick one day as your kindness day. On this day, you are to perform five nice things for yourself, all five in one day. These acts of kindness should be something out of the ordinary that you do for yourself with a little extra effort and may or may not be similar to the acts listed above.' On average, we expected that participants would invest around $10 \mathrm{~min}$ per behavioral activity and sometimes one activity of $1 \mathrm{~h}$, all on one day per week (75 min per week on average).

Participants in the waitlist control condition were told that they were allocated to the flexible group: 'You can choose the activity that fits best to your needs to improve your happiness and well-being. However, before you can choose this activity, we would like to monitor your normal fluctuations in your level of well-being.' At 6 weeks follow-up, the participants in this group chose their activity for which they received the instructions during the following 6 weeks.

\subsection{Outcome Measures}

\subsubsection{Well-being}

The 14-item MHC-SF was used to obtain overall mental well-being which comprises emotional, social and psychological well-being (Keyes et al. 2008; Lamers et al. 2011). Each item was rated on a scale from 0 (never) to 5 (every day). Higher average scores indicate higher levels of mental well-being over the past 4 weeks. In addition, the MHC-SF was used to calculate the number of flourishers. Following Keyes' classification guidelines, participants were considered flourishing when they scored a 4 or 5 on at least one emotional well-being item together with a score of 4 or 5 on at least 6 of the 11 social and psychological well-being items. The reliability of the continuous scale was good in the present study $(\alpha=.87)$.

\subsubsection{Depression}

Participants completed the 20-item CES-D to assess depressive symptoms during the last week (Bouma et al. 1995; Radloff 1977). Scores ranged from 0 (rarely or none of the time (less than 1 day) to 3 (most or all of the time (5-7 days). Four items were recoded before sum scores were calculated (0-60). Higher scores indicate higher levels of depression. The reliability at screening was good $(\alpha=.84)$.

\subsubsection{Anxiety}

The GAD-7 consists of 7 items that measure anxiety symptoms during the past 2 weeks (Donker et al. 2009; Spitzer et al. 2006). The scores ranged from 0 (not at all) to 3 (nearly every day), with higher total scores (0-21) indicating more symptoms of generalized anxiety. A Cronbach's $\alpha$ of .66 at screening showed questionable reliability in the present study. However, the reliability was good at post-test $(\alpha=.88), 6$ weeks follow-up $(\alpha=.87)$ and 6 months follow-up $(\alpha=.88)$. 
Table 3 Raw means (SDs) for mental health outcomes on each assessment by condition

\begin{tabular}{|c|c|c|c|c|c|c|}
\hline & $n$ & $\begin{array}{l}\text { 6-week gratitude } \\
\text { intervention } \\
(n=73)\end{array}$ & $n$ & $\begin{array}{l}\text { Active control } \\
\text { (6-week self-kindness) } \\
(n=73)\end{array}$ & $n$ & $\begin{array}{l}\text { Waitlist control } \\
(n=71)\end{array}$ \\
\hline & & $\mathrm{M}(\mathrm{SD})$ & & $\mathrm{M}(\mathrm{SD})$ & & $\mathrm{M}(\mathrm{SD})$ \\
\hline \multicolumn{7}{|c|}{ Mental well-being } \\
\hline Pretest & 73 & $2.45(.59)$ & 73 & $2.58(.54)$ & 71 & $2.60(.54)$ \\
\hline Post-test & 51 & $3.06(.72)$ & 52 & $2.87(.71)$ & 66 & $2.73(.66)$ \\
\hline 6-week FU & 49 & $2.99(.67)$ & 43 & $2.84(.61)$ & 60 & $2.72(.62)$ \\
\hline 6-months FU & 45 & $3.08(.83)$ & 42 & $3.03(.72)$ & - & - \\
\hline \multicolumn{7}{|c|}{ Generic dispositional gratitude } \\
\hline Pretest & 73 & $4.95(.78)$ & 73 & $4.78(.84)$ & 71 & $5.00(.74)$ \\
\hline Post-test & 51 & $5.45(.86)$ & 51 & $5.11(1.01)$ & 65 & $5.07(.86)$ \\
\hline 6-week FU & 49 & $5.30(.89)$ & 43 & $4.98(.91)$ & 59 & $5.06(.84)$ \\
\hline 6-months FU & 44 & $5.40(.89)$ & 41 & $5.33(.96)$ & - & - \\
\hline \multicolumn{7}{|c|}{ Sense of abundance } \\
\hline Pretest & 73 & $4.45(.88)$ & 73 & $4.40(.82)$ & 71 & $4.54(.97)$ \\
\hline Post-test & 51 & $5.03(.85)$ & 51 & $4.72(.93)$ & 65 & $4.73(1.04)$ \\
\hline 6-week FU & 49 & $4.89(1.14)$ & 43 & $4.76(.85)$ & 59 & $4.68(1.03)$ \\
\hline 6-months FU & 44 & $5.27(.85)$ & 41 & $4.94(.84)$ & - & - \\
\hline \multicolumn{7}{|c|}{ Appreciation of simple pleasures } \\
\hline Pretest & 73 & $4.74(1.07)$ & 73 & $4.84(.88)$ & 71 & $4.76(.97)$ \\
\hline Post-test & 51 & $5.45(1.08)$ & 51 & $5.14(.99)$ & 65 & $5.01(.97)$ \\
\hline 6-week FU & 49 & $5.34(1.22)$ & 43 & $5.14(.91)$ & 59 & $4.79(.98)$ \\
\hline 6-months FU & 44 & $5.59(1.11)$ & 41 & $5.57(.80)$ & - & - \\
\hline \multicolumn{7}{|c|}{ Appreciation of the contribution of others } \\
\hline Pretest & 73 & 4.04 (1.16) & 73 & 3.94 (1.07) & 71 & $3.89(1.36)$ \\
\hline Post-test & 51 & $4.81(1.04)$ & 51 & $4.31(1.34)$ & 65 & $4.12(1.27)$ \\
\hline 6-week FU & 49 & $4.56(1.16)$ & 43 & 4.37 (1.19) & 59 & $3.99(1.19)$ \\
\hline 6-months FU & 44 & $4.84(1.00)$ & 41 & $4.35(1.25)$ & - & - \\
\hline \multicolumn{7}{|l|}{ Grateful mood } \\
\hline Pretest & 73 & $4.63(1.13)$ & 73 & $4.54(1.23)$ & 71 & $4.44(1.16)$ \\
\hline Post-test & 51 & $5.57(1.10)$ & 51 & $4.90(1.23)$ & 64 & $4.62(1.30)$ \\
\hline 6-week FU & 48 & $5.30(1.28)$ & 43 & $4.97(1.19)$ & 59 & $4.55(1.36)$ \\
\hline 6-months FU & 43 & $5.43(1.31)$ & 40 & $4.98(1.16)$ & - & - \\
\hline \multicolumn{7}{|c|}{ Depressive symptoms } \\
\hline Pretest & 73 & $20.97(6.96)$ & 73 & $18.90(7.23)$ & 71 & $19.44(7.71)$ \\
\hline Post-test & 51 & $15.65(10.33)$ & 51 & $15.08(10.20)$ & 64 & $17.78(9.93)$ \\
\hline 6-week FU & 48 & $15.58(9.97)$ & 43 & $13.95(6.83)$ & 59 & $17.69(10.96)$ \\
\hline 6-months FU & 43 & $15.02(11.50)$ & 40 & $15.10(11.05)$ & - & - \\
\hline \multicolumn{7}{|c|}{ Anxiety symptoms } \\
\hline Pretest & 73 & $7.22(2.79)$ & 73 & $5.78(2.85)$ & 71 & $6.31(2.72)$ \\
\hline Post-test & 51 & $5.84(4.11)$ & 51 & $4.76(3.90)$ & 64 & $6.73(4.45)$ \\
\hline 6-week FU & 48 & $5.46(3.23)$ & 43 & $4.79(2.68)$ & 59 & $6.39(5.03)$ \\
\hline 6-months FU & 43 & $5.16(4.32)$ & 40 & $4.92(4.27)$ & - & - \\
\hline
\end{tabular}




\subsubsection{Generic Dispositional Gratitude}

The 6-item Gratitude Questionnaire (GQ-6) was used to assess grateful disposition (Jans-Beken et al. 2015; Emmons et al. 2003). The answer scale ranged from strongly disagree (1) to strongly agree (7). After recoding two negatively formulated items, higher total summed scores ranging from 6 to 42 indicate a higher level of dispositional gratitude. In the present study, the reliability of the scale was questionable $(\alpha=.66)$, but adequate to good at post-test $(\alpha=.78), 6$ weeks follow-up $(\alpha=.75)$ and 6 months follow-up $(\alpha=.81)$.

\subsubsection{Dispositional Characteristics of Gratitude}

The 16-item Short Gratitude Resentment and Appreciation Test (SGRAT) has been developed to assess three specific, trait-like characteristics of gratitude: sense of abundance, appreciation of simple pleasures and appreciation of the contribution of others to one's own well-being (Watkins et al. 2003; Jans-Beken et al. 2015). Each item was scored on an 7-point scale ranging from 1 (strongly disagree) to 7 (strongly agree). Mean scores were calculated of which a higher score indicates higher levels of characteristics of gratitude. The Cronbach's alphas were .76 for sense of abundance, .84 for appreciation of simple pleasures and .85 for appreciation of others.

\subsubsection{Grateful Mood}

Four questions were used to assess grateful mood (McCullough et al. 2004). These questions were: In the past $24 \mathrm{~h}$, (1) ...I felt grateful; (2) ...I was consciously aware that life is good for me; (3) ...I appreciated the simple things in life; (4) ...I felt grateful for what others do and have done for me in my life. Answer categories ranged from 1 (totally disagree) to 7 (totally agree). Higher mean scores indicate a higher level of grateful mood. Cronbach's alpha in the present study was .83 , indicating good reliability.

\subsubsection{Manipulation Check}

Potential differences between expectations and motivation between the gratitude and active control condition were checked using self-developed items at baseline and after the first week in an online happiness-diary. The items about expectations differed slightly between assessments: (1) How convinced are you about the utility of performing well-being exercises for your sustainable happiness and well-being? (2) You now know which well-being exercise you are going to perform. How convinced are you about the utility of performing this exercise for your sustainable happiness and well-being? Furthermore, motivation was measured with the item: How motivated are you for doing this weekly exercise during 6 weeks? All these items were scored on a continuous scale from 1 to 10 , of which 10 is indicating the highest level of expectations or motivation respectively.

\subsubsection{Adherence}

The online happiness-diary was also used to measure weekly adherence. To keep time investment for completing the online diary brief and equal among conditions, 
participants who received the gratitude intervention were asked at the end of each week to write down five experiences or aspects of their lives for which they felt grateful in the past week. Participants in the active control condition were asked the day after they performed the kind acts, to select how many times they had treated themselves yesterday (5 times to 0 times) and what they had done for themselves.

\subsubsection{Client Satisfaction}

At post-test (T1), the participants in the gratitude and active control condition completed the 8-item Client Satisfaction Questionnaire-short form (CSQ-8) to assess the level of client satisfaction (Attkisson and Zwick 1982). Each item has an answer scale from 1 to 4, but the labels differ per item. Five items were recoded as such that a higher sum score (8-32) indicated higher satisfaction with the exercise. The Cronbach's alpha showed excellent reliability in the current study (.93). In addition, participants were asked about how much time they had spent on doing the exercise each week, on average ( $1=$ less than 15 min per week, $5=$ more than $2 \mathrm{~h}$ per week) and how they evaluated the exercise in general on a continuous scale from 1 to 10 , of which 10 is indicating the highest level of satisfaction.

\subsection{Statistical Analysis}

Descriptive statistics of demographic variables and outcome measures at baseline were calculated and compared between conditions using $\chi^{2}$-tests and univariate analysis of variance (ANOVA) in SPSS version 25.0, using two-tailed tests and $p<.05 . X^{2}$-tests and ANOVAs were also used to determine whether the number of drop-outs differed per condition and whether drop-outs (i.e. participants who completed only the baseline assessment) differed from participants who completed at least two assessments. Adherence was defined as reporting at least four grateful things or activities for themselves during at least 4 of the 6 weeks. The difference in adherence between the gratitude and active control condition was examined using $\chi^{2}$-tests.

Changes in outcome measures over time were examined using multilevel growth curve modeling in $R$ (version 0.99.902, NLME package) to account for repeated measures nested within individuals (Singer and Willett 2003). This method also complies with the intention-to-treat principal because all randomized individuals are included in the analyses. First, we tested the efficacy of the 6-week gratitude intervention compared to active control and waitlist control up to 6 weeks follow-up using an unconditional growth curve model, specifying linear and quadratic changes over time. The unconditional quadratic growth model best fitted the data on all outcomes $\left(>\Delta \chi^{2}(10)=18.19, p=.001\right)$. Therefore, the baseline unconditional quadratic growth model was compared with the hypothesis-testing models. Time was centered on the second time point (post-test) and each condition was dummy-coded.

Composite model: $Y_{\mathrm{ij}}=\gamma_{00}+\gamma_{10}$ Time $_{\mathrm{ij}}+\gamma_{20} \operatorname{Time}^{2}{ }_{\mathrm{ij}}\left(\varepsilon_{\mathrm{ij}}+\zeta_{\mathrm{oi}}+\zeta_{1 \mathrm{i}}\right.$ Time $_{\mathrm{ij}}+\zeta_{2 \mathrm{i}}$ Time $\left.^{2}{ }_{\mathrm{ij}}\right)$.

Level 1 model: $\mathrm{Y}_{\mathrm{ij}}=\pi_{0 \mathrm{i}}+\pi_{1 \mathrm{i}}$ Time $_{\mathrm{ij}}+\pi_{2 \mathrm{i}}$ Time $_{\mathrm{ij}}^{2}+\varepsilon_{\mathrm{ij}}$.

Level 2 models: $\pi_{0 \mathrm{i}}=\gamma_{00}+\zeta_{0 \mathrm{i}}, \pi_{1 \mathrm{i}}=\gamma_{10}+\zeta_{1 \mathrm{i}}$, and $\pi_{2 \mathrm{i}}=\gamma_{20}+\zeta_{2 \mathrm{i}}$.

Secondly, we tested the efficacy of the 6-week gratitude intervention up to 6 months follow-up only with the active control condition because the waitlist control had started 
with their self-chosen well-being activity after 6 weeks follow-up. Again, the unconditional quadratic growth model was compared with the hypothesis-testing models.

Finally, post-hoc Cohen's $d$ effect sizes were calculated for significant and marginally significant findings from multilevel growth curve analyses and based on completers only data. For this, means at post-test and follow-up assessments were adjusted for baseline differences using analysis of covariance, in which the post-test or follow-up mean scores were entered as dependent variable and the corresponding baseline mean score as covariates. Between-group effect sizes were then calculated by subtracting the adjusted mean scores of the gratitude condition from the adjusted mean score of one of the control conditions at each time point, and dividing the mean difference by the pooled standard deviation. The 95\% confidence intervals (CI's) of Cohen's $d$ were computed in R.

\section{Results}

\subsection{Manipulation Check}

At baseline, participants in the gratitude and active control condition were strongly convinced about the utility of doing a well-being exercise $(M=7.0, S D=1.52)$, which decreased somewhat after the first week of practicing their exercise $(M=6.7, S D=1.65)$. Participants were also highly motivated to practice in the upcoming weeks $(M=8.0$, $S D=1.10)$, which was still satisfactorily after the first week intervention $(M=7.6$, $S D=1.78$ ). More importantly, expectations and motivation did not significantly differ between both conditions at any assessment $(p>.652)$, except for the expectations after one week practice. The participants in the gratitude intervention were significantly more convinced about the utility of this exercise for their well-being compared to active control $\left(\mathrm{M}_{\text {gratitude }}=7.16, \mathrm{SD}=1.33 ; \mathrm{M}_{\text {activecontrol }}=6.31, \mathrm{SD}=1.81, F(130)=9.26, p=.003\right)$.

\subsection{Drop-out and Adherence}

A total of 176 participants $(81.1 \%)$ completed at least two of the four questionnaires. Drop-out was highest at 6 months follow-up (36.9\%). The total number of drop-outs, as well as the number of drop-outs at post-test and at 6 weeks follow-up, were significantly lower in the waitlist condition compared to the other two conditions, $\chi^{2}(2)=12.51$, $p=.002 ; \chi^{2}(2)=13.97, p=.001 ; \chi^{2}(2)=11.69, p=.003$ respectively. Drop-outs were significantly younger, $F(215)=10.44, p=.001$ and they scored significantly lower on generic dispositional gratitude, $F(215)=6.31, p=.013$ and marginally lower on appreciation of others $F(215)=3.70, p=.056$. No other differences on socio-demographics or baseline measures were found between drop-outs and completers.

Almost half of the participants of the intervention and active control condition adhered to the program (47.9\%). However, adherence was significantly greater for the 6-week gratitude intervention compared to performing self-kindness, $57.5 \%$ vs. $38.4 \% ; \chi^{2}(1)=5.38, p=.020$. This difference in favor of the gratitude intervention was also visible during most weeks $(p s<.007)$, except for week 3 and 4 where adherence did not significantly differ between groups $(p s>.185)$. Overall adherence was highest in week $1(78.1 \%)$ and week $2(63 \%)$, and lowest in week $4(41.8 \%)$ and week $5(42.5 \%)$. 


\subsection{Efficacy of Gratitude versus Active Control}

The raw means and standard deviations for all outcomes on each assessment are presented in Table 3. The gratitude intervention was more effective in enhancing wellbeing, $\gamma_{21}=-.21$, S.E. $=.08, t(315)=-2.63, p=.009$, appreciation of simple pleasures, $\gamma_{21}=-.30$, S.E. $=.12, t(312)=-2.57, p=.011$, appreciation of the contribution of others, $\gamma_{21}=-.34$, S.E. $=.16, t(312)=-2.08, p=.038$, and grateful mood, $\gamma_{21}=-.43$, S.E. $=.20, t(310)=-2.22, p=.027$, compared to the active control condition (Table 4). Mainly significant quadratic increases over time were found, indicating that the gratitude intervention led to stronger effects up to post-test, followed by a slight decline when participants were no longer directly stimulated to practice gratitude. However, well-being also showed a marginal linear increase over time, $\gamma_{11}=.10$, S.E. $=.05$, $t(315)=1.81, p=.072$. No significant changes over time were found for generic dispositional gratitude as measured by the GQ-6, sense of abundance, depression and anxiety compared to active control. Effect sizes at post-test were $d=.63(95 \% \mathrm{CI}=.23-1.02)$ for mental well-being, $d=.61$ for appreciation of simple pleasure $(95 \% \mathrm{CI}=.21-1.01)$, $d=.48$ for appreciation of contribution of others $(95 \% \mathrm{CI}=.09-.87)$ and $d=.53$ for grateful mood (95\% CI=.13-.92). At 6 weeks follow-up, effect sizes were $d=.40(95 \%$ $\mathrm{CI}=-.01-.81)$ for mental well-being, $d=.28$ for appreciation of simple pleasure $(95 \%$ $\mathrm{CI}=-.13-.69), d=.09$ for appreciation of contribution of others $(95 \% \mathrm{CI}=-.32-.50)$ and $d=.15$ for grateful mood $(95 \% \mathrm{CI}=-.26-.56)$.

\subsection{Efficacy of Gratitude versus Waitlist Control}

Practicing gratitude led to significant linear and quadratic increases over time relative to waitlist control for well-being, $\gamma_{11}=.18$, S.E. $=.05, t(315)=3.55, p<.001$; $\gamma_{21}=-.28$, S.E. $=.07, t(315)=-3.80, p<.001$ and appreciation of the contribution of others, $\gamma_{11}=.18$, S.E. $=.09, t(312)=1.97, p=.050 ; \gamma_{21}=-.33$, S.E. $=.16, t(312)=-2.13$, $p=.034$. In addition, greater quadratic changes and marginal linear changes in favor of practicing gratitude were found for grateful mood, $\gamma_{21}=-.50$, S.E. $=.18, t(310)=-2.69$, $p=.008 ; \gamma_{11}=.20$, S.E. $=.11, t(310)=1.73, p=.084$ and for sense of abundance, $\gamma_{11}=.15$, S.E. $=.07, t(312)=2.12, p=.035 ; \gamma_{21}=-.20$, S.E. $=.11, t(312)=-1.78, p=.076$. Furthermore, practicing gratitude led to significant quadratic, but not linear, changes over time in generic dispositional gratitude, $\gamma_{21}=-.26$, S.E. $=.011 t(313)=-2.35, p=.020$ and in greater linear, but not quadratic, changes in appreciation of simple pleasures, $\gamma_{11}=.23$, S.E. $=.08, t(312)=2.76, p=.006$. Finally, marginal linear decreases were found for anxiety symptoms, $\gamma_{11}=-.69$, S.E. $=.38, t(310)=-1.82, p=.070$, while changes in depressive symptoms were not significant compared to waitlist control. At post-test, effect sizes were $d=.93(95 \% \mathrm{CI}=.54-1.31)$ for mental well-being, $d=.61$ for appreciation of simple pleasure (95\% $\mathrm{CI}=.23-.98), d=.65$ for appreciation of contribution of others (95\% CI $=.27-1.02), d=.80$ for grateful $\operatorname{mood}(95 \% \mathrm{CI}=.42-1.18), d=.53$ for sense of abundance $(95 \% \mathrm{CI}=.16-.90), d=.33$ for anxiety symptoms $(95 \% \mathrm{CI}=-.04-.70)$ and $d=.51$ for dispositional gratitude $(95 \% \mathrm{CI}=.14-.88)$. Effect sizes at 6 weeks follow-up were $d=.66(95 \% \mathrm{CI}=.27-1.05)$ for mental well-being, $d=.61$ for appreciation of simple pleasure $(95 \% \mathrm{CI}=.22-1.00), d=.49$ for appreciation of contribution of others $(95 \%$ $\mathrm{CI}=.10-.87), d=.47$ for grateful mood $(95 \% \mathrm{CI}=.08-.85), d=.41$ for sense of abundance $(95 \% \mathrm{CI}=.03-.79), d=.27$ for anxiety symptoms $(95 \% \mathrm{CI}=-.11-.65)$ and $d=.31$ for dispositional gratitude $(95 \% \mathrm{CI}=-.07-.69)$. 


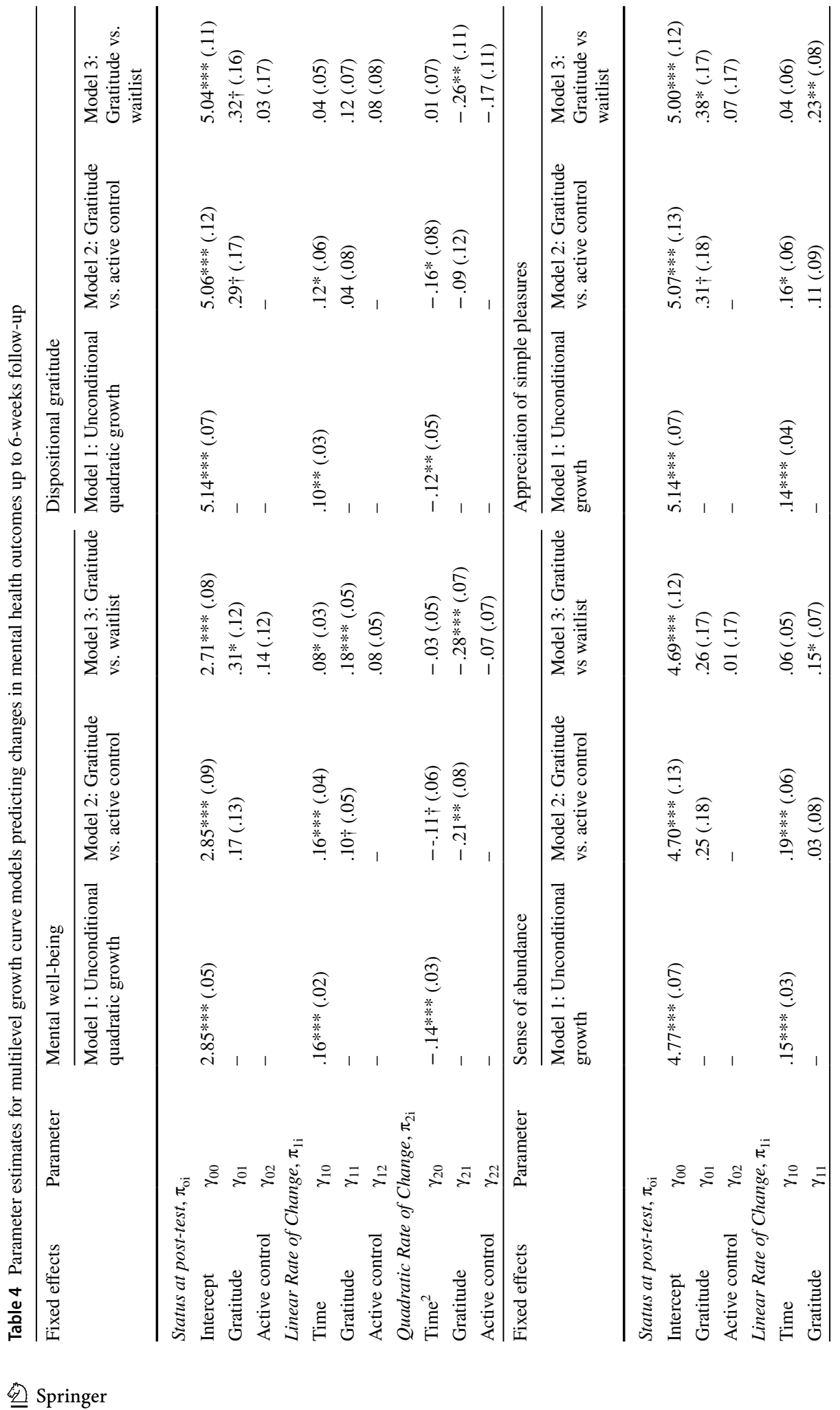




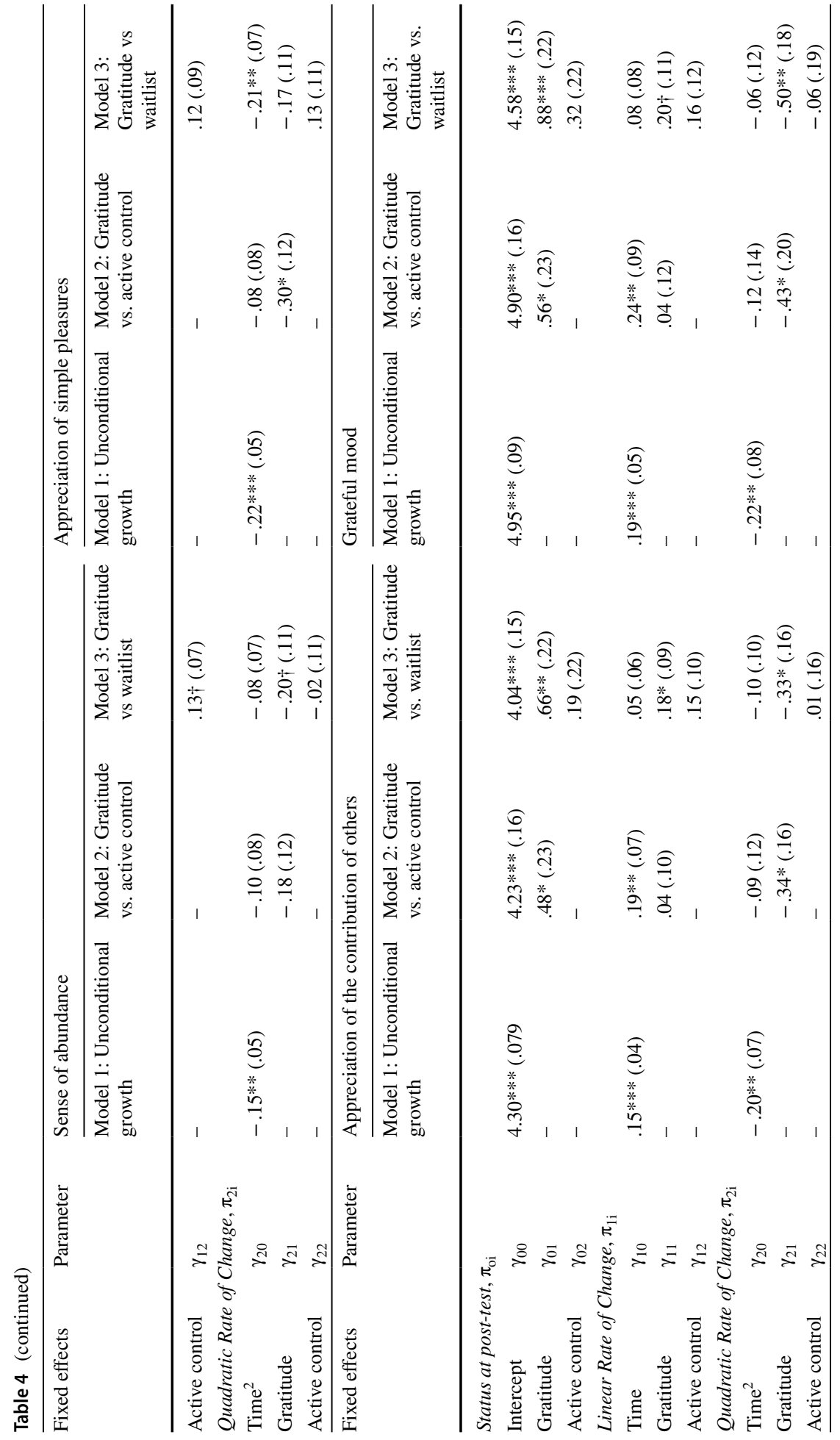




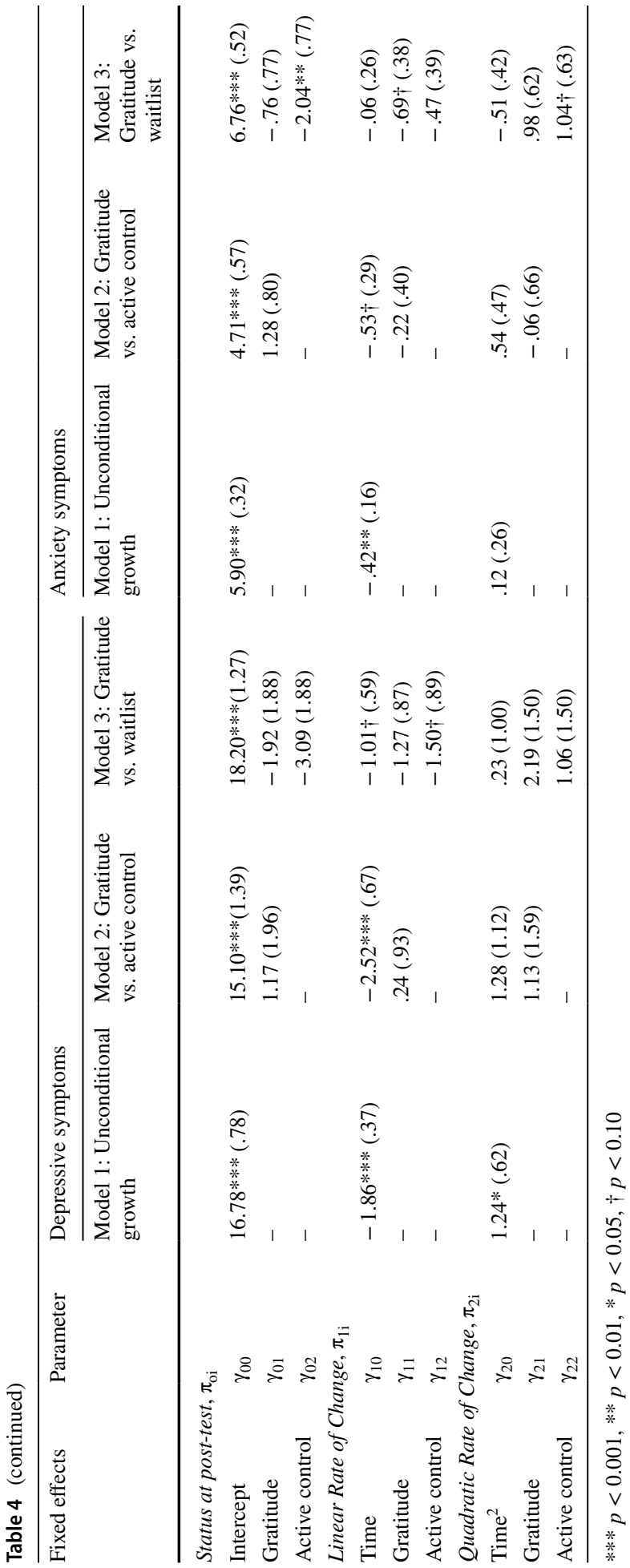


Unexpectedly, practicing self-kindness (the active control condition) was marginally more effective in decreasing anxiety and depressive symptoms compared to waitlist control. Marginal linear shifts in depressive symptoms were found $\left(\gamma_{12}=1.50\right.$, S.E. $=.89, t(310)=1.68$, $p=.094)$ and marginal quadratic shifts in anxiety symptoms $\left(\gamma_{22}=1.04\right.$, S.E. $=.63$, $t(310)=1.67, p=.096)$. Effect sizes were $d=.29$ (95\% CI=-.08-.66) for depressive symptoms and $d=.45$ for anxiety symptoms $(95 \% \mathrm{CI}=.08-.82)$ at post-test. At 6 weeks follow-up, effect sizes were $d=.37$ (95\% $\mathrm{CI}=-.03-.77)$ for depressive symptoms and $d=.32$ for anxiety symptoms $(95 \% \mathrm{CI}=-.08-.71)$. These findings show that reducing anxiety and depressive symptoms was most successful when participants practiced self-kindness during 6 weeks compared to doing nothing, while practicing gratitude did not lead to a significant reduction in these mental health indicators.

\subsection{Changes up to 6-Months Follow-up}

To test the overall efficacy of practicing gratitude up to 6-months, we repeated the analyses using a quadratic growth model wherein we compared the gratitude condition solely with the active control condition as the waitlist had started their intervention after 6-weeks follow-up. Practicing gratitude led to significantly greater linear and quadratic changes over time in mental well-being, $\gamma_{11}=.13$, S.E. $=.05, t(278)=2.34, p=.020 ; \gamma_{21}=-.08$, S.E. $=.04$, $t(278)=-1.98, p=.048$, and to greater quadratic changes and marginal linear changes over time in simple pleasure appreciation, $\gamma_{21}=-.12$, S.E. $=.06, t(275)=-2.15, p=.033 ; \gamma_{11}=.14$, S.E. $=.08, t(275)=1.75, p=.081$. No other significant changes were found, suggesting that practicing gratitude was not more successful than practicing self-kindness in improving generic dispositional gratitude, sense of abundance, appreciation of the contribution of others and grateful mood, and in reducing depressive symptoms and anxiety symptoms over the long-run. Effect sizes at 6-months follow-up were $d=.31$ for mental well-being (95\% $\mathrm{CI}=-.12-.73)$ and $d=.17$ for appreciation of simple pleasure (95\% $\mathrm{CI}=-.26-.60)$.

\subsection{Client Satisfaction}

Participants in the gratitude intervention were significantly more satisfied with their gratitude exercises $(M=23.67, S D=5.14)$ compared to active control $(M=19.75, S D=4.80)$ as reported at post-test, $F(101)=15.85, p<.001$. When satisfaction was expressed in a grade from 1 to 10 , a similar result was found with a $7.2(\mathrm{SD}=1.62)$ for practicing gratitude and a 5.9 (SD (1.82) for practicing self-kindness, $F(101)=15.32, p<.001$. However, both groups spent a similar amount of time to practice their well-being exercise $(p=.505)$ of which most participants practiced 30 to $60 \mathrm{~min}$ per week $(34.3 \%$; gratitude $=35.3 \%$, self-kindness $=33.3 \%)$ or $15-30$ min per week $(31.4 \%$; gratitude $=27.5 \%$, self-kindness $=35.3 \%$ ). In addition, $20.6 \%$ of the participants practiced between 1 and $2 \mathrm{~h}$ per week (gratitude $=25.5 \%$, self-kindness $=15.7 \%$ ) and $6.9 \%$ of the participants spent more than $2 \mathrm{~h}$ per week on the intervention (gratitude $=2.0 \%$, self-kindness $=11.8 \%$ ).

\section{Discussion}

The aim of the current study was to assess the impact of a 6-weeks gratitude intervention on mental well-being, depression, anxiety and gratitude and to address some important gaps in the current knowledge about the efficacy of gratitude interventions (Davis et al. 
2016). Therefore, our objectives were to evaluate the impact of practicing gratitude on mental health for people with low to moderate well-being and moderate distress, to assess the effects of gratitude up to 6 months follow-up and to assess the effects on gratitude as a mood in addition to generic dispositional gratitude and specific dispositional gratitude characteristics.

\subsection{Effects on Mental Well-Being}

The findings demonstrated that practicing gratitude was more effective in improving mental well-being in comparison to both active and waitlist control. The moderate to large effects on mental well-being relative to active and waitlist control at post-intervention were larger than has generally been found in studies on the efficacy of gratitude interventions (Davis et al. 2016). One explanation may be that the participants experienced suboptimal levels of well-being, allowing more room for improvement. Many studies have been evaluating the impact of gratitude interventions in healthy populations, thereby minimalizing the potential benefits due to a ceiling effect (Davis et al. 2016). A second explanation for the stronger effects found in the current study in comparison to earlier studies may be that, to date, most gratitude interventions were of short duration, i.e. one or two weeks focusing on a single activity such as writing a gratitude letter or making a gratitude list. Finding the optimal dosage of interventions is an important challenge in the field of positive psychology (Lyubomirsky and Layous 2013) and the current study indicates that extending gratitude interventions to 6 weeks, including various gratitude activities may enhance their impact. Directly comparing gratitude interventions of 2, 4 and 6 weeks would give more direct evidence of their optimal duration. A third explanation for the larger effects is that the exercises in the gratitude intervention were much more varied than in other studies, making the intervention less vulnerable to hedonic adaption (Sheldon and Lyubomirsky 2012; Lyubomirsky et al. 2005). Participants in the gratitude condition were instructed to practice different exercises at a daily basis, which might have kept the participants more motivated. In fact, adherence was greater in the gratitude intervention compared to active control and the participants who received the gratitude intervention were significantly more satisfied with this intervention compared to those who were instructed to perform five nice things for themselves on one day each week during 6 weeks. However, these findings also indicate that the found effects in comparison to active control might have been due to the frequency of practice and not to the type of intervention. Although the needed time to perform weekly gratitude or self-kindness activities did not differ in the current study, future research should use an active control activity that also controls for the variability of the gratitude intervention to ensure its efficacy also in comparison to another active intervention.

Interestingly, the findings of this study showed that the effects of practicing gratitude on mental well-being were maintained up to 6 months follow-up. This is one of the first studies to assess the longer term impact of gratitude interventions (Davis et al. 2016). This sustainable impact on mental well-being is relevant as lower levels of mental well-being have been found to increase the risk for first and recurrent incidence of psychopathology and diagnosed mental disorders (e.g. Schotanus-Dijkstra et al. 2017; Lamers et al. 2015; Keyes et al. 2010; Wood and Joseph 2010). Given the large numbers of people with suboptimal well-being (Schotanus-Dijkstra et al. 2016) and with distress and common mental disorders in the general population (de Graaf et al. 2012; Whiteford et al. 2013), there is a need for easy-to-administer and low-intensity interventions in the context of public mental health (e.g. Huppert 2004; Schotanus-Dijkstra et al. 2019a; Fledderus et al. 2012; Kobau 
et al. 2011). The participants in the present study practiced gratitude without any guidance, suggesting the intervention can be administered at low costs.

\subsection{Effects on Distress}

The results also showed that levels of symptomatology of depression and anxiety diminished in the gratitude intervention group, but that these changes were not significantly different in comparison with active or waitlist control. The non-significant findings of gratitude versus waitlist control were unexpected as earlier studies have found that gratitude promotes positive emotions and coping-styles such positive reframing and acceptance which are associated with reduced distress (e.g. Wood et al. 2007; Lambert et al. 2012). One explanation is that the participant in the waitlist condition also improved, resulting in comparable levels of distress in both groups.

Also, reductions in distress were found to be marginally larger for the participants practicing self-kindness in comparison to waitlist on the short-term. This finding may be explained by the fact that the participants in the active control condition were invited to do five nice things for themselves on one day a week for six weeks. These activities may have supported participants in developing a more compassionate stance towards themselves (Nelson et al. 2016), which has been shown to be positively associated with reduced distress in earlier studies (Kirby et al. 2017; MacBeth and Gumley 2012). Another explanation is that performing acts of kindness for oneself will enhance the experience of positive emotions. Amplifying positive emotions has been shown to be an effective pathway in promoting well-being, increasing resilience and diminishing distress (Fredrickson 2001, 1998; Fredrickson et al. 2003). In sum, these findings indicate that practicing self-kindness might also be a low-benefit intervention, but then on targeting depressive and anxiety symptoms in people with reduced levels of well-being and low to moderate levels of distress (Kirby et al. 2017; Shin and Lyubomirsky 2017). However, more research is needed as the effects of self-kindness might differ from self-indulgence of which the latter was intended in the current study.

\subsection{Effects on Gratitude}

To our knowledge this is one of the first studies to directly compare the impact of a gratitude intervention on various measures of gratitude. The outcome instruments included generic dispositional gratitude (GQ, McCullough et al. 2002), three specific dispositional characteristics of grateful persons: sense of abundance, appreciating simple pleasures and relational gratitude (GRAT, Watkins et al. 2003) and gratitude as a mood (McCullough et al. 2004). The findings demonstrated that the gratitude intervention led to greater increases in all of these outcomes compared to waitlist control, of which the effects at posttest and at 6-weeks follow-up were mainly of moderate to large magnitude. The gratitude intervention was also more effective compared to active control on appreciating simple pleasures, relational gratitude and grateful mood. However, only the overall efficacy of appreciating simple pleasures maintained up to 6-months follow-up, although the difference at this latter time-point was also (marginally) in favor of practicing gratitude compared to active control for relational gratitude and grateful mood.

The current findings are in contrast with a recent meta-analysis which demonstrated the absence of effects on gratitude in comparison with measurement-only control (Davis et al. 2016). A possible explanation for this discrepancy is the longer duration of the intervention 
in the current study in comparison to most interventions included in the meta-analysis. In addition, most studies evaluated the impact of gratitude interventions on (generic) dispositional gratitude (Davis et al. 2016), while the current study is one of the first to also report the effects of gratitude interventions on gratitude as mood. Dispositional gratitude represents a more stable trait that may be harder to change over time. This may explain the limited impact of gratitude interventions on dispositional gratitude (Davis et al. 2016), although the findings of the current study suggest that a variable 6-week gratitude intervention can effectively improve dispositional gratitude as well. In contrast to dispositional gratitude, moods could be more easily influenced by intentions to be grateful (McCullough et al. 2004). For example, in the current gratitude intervention, the participants were invited to start each day, after waking-up, with focusing on their intention to be appreciative of small good things in life and of positive contributions of others. This may have contributed to a lasting appreciative perspective on one's life and a resulting grateful mood. Also, though of shorter duration and less stable than traits, moods certainly last longer than emotional states and thus represent an intermediate level between gratitude as an affective trait and gratitude as an emotion (Rosenberg 1998). The presence of a grateful mood will promote the occurrence of positive emotions and contribute to upward spirals in daily life (McCullough et al. 2004; Catalino and Fredrickson 2011; Watkins et al. 2015). Our findings suggest that grateful mood is a good proximal outcome of gratitude interventions in addition to dispositional gratitude (Davis et al. 2016; Wood et al. 2010).

Next to grateful mood, strongest effects were found for the appreciation of the contribution of others. This finding suggests that the effects on relational gratitude is a core aspect of gratitude, for example through the recognition and appreciation of receiving specific benefits from other persons (e.g. McCullough et al. 2002; Wood et al. 2009; Watkins et al. 2003). Participants practicing gratitude have become more appreciative of the contribution of others to their well-being in comparison to the participants practicing self-kindness. This is relevant because many recent studies have demonstrated the positive impact of experiencing and expressing gratitude on maintaining relationships (e.g. Grant and Gino 2010; Algoe and Zhaoyang 2016; Lambert and Fincham 2011) and improving relationships (e.g. Algoe 2012; Algoe et al. 2010; Bartlett et al. 2012).

Lastly, the effects on appreciation of simple pleasures were sustained up to 6 months follow-up in comparison with active control. A longer term comparison with waitlist control was not possible but might have yielded even more and stronger results as was also found up to 6-week follow-up. These findings are relevant because recent research suggests that gratitude is an adaptive resource promoting and maintaining mental health, also in the presence of negative life-events (e.g. Wood et al. 2010; Disabato et al. 2016; Millstein et al. 2016; Sirois and Wood 2017; Kashdan et al. 2006). However, longer term comparison to a more equal active control group and to waitlist control is needed to draw firm conclusion on the sustainability of the gratitude effects of practicing gratitude.

\section{Limitations}

Some important limitations apply to the current study. First, the findings in comparison with the active control condition should be interpreted with caution. The instructions for the active control condition were more static and repetitive while the gratitude intervention was more variable. This might have led to a more motivated group of participants and exemplify the frequency of practice rather than the efficacy of the content of the 
intervention as was also visible in a higher level of expectation, satisfaction and adherence in the gratitude intervention compared to active control, despite a similar amount of time spent per week on each intervention. Future research might want to compare the 6-week gratitude intervention with a variable 6-week intervention with a focus on self-kindness. Adherence - as measured in an online diary — could then also be more content related (e.g. Did you perform the exercise as instructed this week? On how many days did you perform the exercise?). Also, it is important to note that gratitude is other-oriented while self-kindness is self-oriented. A more conceptually equivalent condition to gratitude would be performing kind acts for others as in both these interventions reduction of self-preoccupation could be an important process. For future research performing acts of kindness for others is recommend as active control condition.

Secondly, higher educated women were over-represented in the current study and the findings cannot be generalized to the general population. Thirdly, Cronbach's alpha of anxiety and dispositional gratitude in the current sample were questionable which might have influenced outcomes. However the Cronbach's alphas were more satisfactorily at later time-points. Fourthly, no diagnostic interviews were conducted so it is unknown how many participant met the criteria for a mood or anxiety disorder at baseline.

\section{Conclusion}

Despite the limitations, the results of this study suggest that a 6-week gratitude intervention is an effective, low-intensity intervention for enhancing mental well-being and various gratitude measures but not distress among people with low to moderate levels of well-being and low or moderate distress, at least in higher-educated women. The sustained effects on mental well-being appreciation of simple pleasure up to 6-months follow-up, suggest that it is possible to promote an appreciative and grateful perspective on life that becomes a lasting resource for living a resilient, joyful and meaningful life.

\section{Conflict of Interest}

The authors declare that the research was conducted in the absence of any commercial or financial relationships that could be construed as a potential conflict of interest.

Open Access This article is licensed under a Creative Commons Attribution 4.0 International License, which permits use, sharing, adaptation, distribution and reproduction in any medium or format, as long as you give appropriate credit to the original author(s) and the source, provide a link to the Creative Commons licence, and indicate if changes were made. The images or other third party material in this article are included in the article's Creative Commons licence, unless indicated otherwise in a credit line to the material. If material is not included in the article's Creative Commons licence and your intended use is not permitted by statutory regulation or exceeds the permitted use, you will need to obtain permission directly from the copyright holder. To view a copy of this licence, visit http://creativecommons.org/licenses/by/4.0/.

\section{References}

Algoe, S. B. (2012). Find, remind, and bind: The functions of gratitude in everyday relationships. Social and Personality Psychology Compass, 6(6), 455-469. 
Algoe, S. B., Gable, S. L., \& Maisel, N. C. (2010). It's the little things: Everyday gratitude as a booster shot for romantic relationships. Personal relationships, 17(2), 217-233.

Algoe, S. B., \& Zhaoyang, R. (2016). Positive psychology in context: Effects of expressing gratitude in ongoing relationships depend on perceptions of enactor responsiveness. The Journal of Positive Psychology, 11(4), 399-415.

Attkisson, C. C., \& Zwick, R. (1982). The client satisfaction questionnaire. Psychometric properties and correlations with service utilization and psychotherapy outcome. Evaluation and Program Planning, 5(3), 233-237.

Bartlett, M. Y., Condon, P., Cruz, J., Baumann, J., \& Desteno, D. (2012). Gratitude: Prompting behaviours that build relationships. Cognition and Emotion, 26(1), 2-13.

Bouma, J., Ranchor, A. V., Sanderman, R., \& van Sonderen, E. (1995). Het meten van symptomen van depressie met de CES-D. Een handleiding. Groningen: Noordelijk Centrum voor Gezondheidsvraagstukken.

Catalino, L. I., \& Fredrickson, B. L. (2011). A Tuesday in the life of a flourisher: The role of positive emotional reactivity in optimal mental health. Emotion, 11(4), 938-950. https://doi.org/10.1037/ a0024889.

Cloninger, C. R. (2006). The science of well-being: An integrated approach to mental health and its disorders. World Psychiatry, 5(2), 71.

Davis, D. E., Choe, E., Meyers, J., Wade, N., Varjas, K., Gifford, A., et al. (2016). Thankful for the little things: A meta-analysis of gratitude interventions. Journal of Counseling Psychology, 63(1), 20-31. https://doi.org/10.1037/cou0000107.

de Graaf, R., ten Have, M., van Gool, C., \& van Dorsselaer, S. (2012). Prevalence of mental disorders and trends from 1996-2009. Results from The Netherlands mental health survey and incidence study-2. Social Psychiatry and Psychiatric Epidemiology, 47(2), 203-213. https://doi.org/10.1007/ s00127-010-0334-8.

de Vos, J. A., Radstaak, M., Bohlmeijer, E. T., \& Westerhof, G. J. (2018). Having an eating disorder and still being able to flourish? examination of pathological symptoms and well-being as two continua of mental health in a clinical sample. [Original Research]. Frontiers in Psychology. https:// doi.org/10.3389/fpsyg.2018.02145.

Dickens, L. R. (2017). Using gratitude to promote positive change: a series of meta-analyses investigating the effectiveness of gratitude interventions. Basic and Applied Social Psychology, 39(4), 193-208.

Disabato, D. J., Goodman, F. R., Kashdan, T. B., Short, J. L., \& Jarden, A. (2016). Different types of well-being? A cross-cultural examination of hedonic and eudaimonic well-being. Psychological Assessment, 28(5), 471.

Donker, T., van Straten, A., Marks, I., \& Cuijpers, P. (2009). A brief web-based screening questionnaire for common mental disorders: Development and validation. Journal of Medical Internet Research, 11(3), e19.

Emmons, R. A., \& McCullough, M. E. (2003). Counting blessings versus burdens: An experimental investigation of gratitude and subjective well-being in daily life. Journal of Personality and Social Psychology. https://doi.org/10.1037/0022-3514.84.2.377.

Emmons, R. A., McCullough, M. E., \& Tsang, J.-A. (2003). The assessment of gratitude. In S. J. Lopez \& C. R. Snyder (Eds.), Positive psychological assessment: A handbook of models and measures (pp. 327-341). American Psychological Association.

Emmons, R. A., \& Stern, R. (2013). Gratitude as a psychotherapeutic intervention. Journal of Clinical Psychology, 69(8), 846-855. https://doi.org/10.1002/jclp.22020.

Fledderus, M., Bohlmeijer, E. T., Pieterse, M. E., \& Schreurs, K. M. (2012). Acceptance and commitment therapy as guided self-help for psychological distress and positive mental health: A randomized controlled trial. Psychological Medicine, 42(3), 485-495. https://doi.org/10.1017/S0033291711001206.

Franken, K., Lamers, S. M. A., Ten Klooster, P. M., Bohlmeijer, E. T., \& Westerhof, G. J. (2018). Validation of the mental health continuum-short form and the dual continua model of well-being and psychopathology in an adult mental health setting. Journal of Clinical Psychology. https://doi. org/10.1002/jclp.22659.

Fredrickson, B. L. (1998). What Good Are Positive Emotions? Review of general psychology : Journal of Division 1, of the American Psychological Association, 2(3), 300-319. https://doi. org/10.1037/1089-2680.2.3.300.

Fredrickson, B. L. (2001). The Role of positive emotions in positive psychology: The Broaden-and-build theory of positive emotions. The American psychologist, 56(3), 218-226.

Fredrickson, B. L., Tugade, M. M., Waugh, C. E., \& Larkin, G. R. (2003). What good are positive emotions in crises? A prospective study of resilience and emotions following the terrorist attacks on the United States on September 11th, 2001. Journal of Personality and Social Psychology, 84(2), 365-376. 
Grant, A. M., \& Gino, F. (2010). A little thanks goes a long way: Explaining why gratitude expressions motivate prosocial behavior. Journal of Personality and Social Psychology, 98(6), 946.

Grant, F., Guille, C., \& Sen, S. (2013). Well-being and the risk of depression under stress. PLoS ONE, 8(7), e67395. https://doi.org/10.1371/journal.pone.0067395.

Huppert, F. A. (2004). A population approach to positive psychology: The potential for population interventions to promote well-being and prevent disorder. In P. A. Linley \& S. Joseph (Eds.), Positive psychology in practice (pp. 693-709). Hoboken, NJ, US: John Wiley.

Isaacowitz, D. M., Vaillant, G. E., \& Seligman, M. E. (2003). Strengths and satisfaction across the adult lifespan. International Journal of Aging and Human Development, 57(2), 181-201.

Jans-Beken, L., Lataster, J., Leontjevas, R., \& Jacobs, N. (2015). Measuring gratitude: A comparative validation of the Dutch gratitude questionnaire (GQ6) and short gratitude, resentment, and appreciation test (SGRAT). Psychologica Belgica, 55(1), 19.

Kashdan, T. B., Uswatte, G., \& Julian, T. (2006). Gratitude and hedonic and eudaimonic well-being in Vietnam war veterans. Behaviour Research and Therapy, 44(2), 177-199.

Kerr, S. L., O’Donovan, A., \& Pepping, C. A. (2015). Can gratitude and kindness interventions enhance well-being in a clinical sample? Journal of Happiness Studies, 16(1), 17-36. https://doi.org/10.1007/ s10902-013-9492-1.

Keyes, C. L., Wissing, M., Potgieter, J. P., Temane, M., Kruger, A., \& van Rooy, S. (2008). Evaluation of the mental health continuum-short form (MHC-SF) in setswana-speaking South Africans. Clinical Psychology and Psychotherapy, 15(3), 181-192. https://doi.org/10.1002/cpp.572.

Keyes, C. L. M. (2005). Promoting and protecting mental health as flourishing: a complementary strategy for improving national mental health. American Psychologist. https://doi.org/10.1037/0003-066x.62.2.95.

Keyes, C. L. M., Dhingra, S. S., \& Simoes, E. J. (2010). Change in level of positive mental health as a predictor of future risk of mental illness. American Journal of Public Health, 100(12), 2366-2371. https:// doi.org/10.2105/AJPH.2010.192245.

Kirby, J. N., Tellegen, C. L., \& Steindl, S. R. (2017). A meta-analysis of compassion-based interventions: Current state of knowledge and future directions. Behavior Therapy, 48(6), 778-792.

Kobau, R., Seligman, M. E., Peterson, C., Diener, E., Zack, M. M., Chapman, D., et al. (2011). Mental health promotion in public health: Perspectives and strategies from positive psychology. American Journal of Public Health, 101(8), e1-9. https://doi.org/10.2105/AJPH.2010.300083.

Lambert, N. M., \& Fincham, F. D. (2011). Expressing gratitude to a partner leads to more relationship maintenance behavior. Emotion, 11(1), 52.

Lambert, N. M., Fincham, F. D., \& Stillman, T. F. (2012). Gratitude and depressive symptoms: the role of positive reframing and positive emotion. Cognition and emotion, 26, 615-633.

Lamers, S. M. A., Westerhof, G. J., Bohlmeijer, E. T., ten Klooster, P. M., \& Keyes, C. L. M. (2011). Evaluating the psychometric properties of the mental health continuum-short form (MHC-SF). Journal of Clinical Psychology, 67(1), 99-110. https://doi.org/10.1002/jclp.20741.

Lamers, S. M. A., Westerhof, G. J., Glas, C. A. W., \& Bohlmeijer, E. T. (2015). The bidirectional relation between positive mental health and psychopathology in a longitudinal representative panel study. The Journal of Positive Psychology, 10(6), 553-560. https://doi.org/10.1080/17439760.2015.1015156.

Lyubomirsky, S., \& Layous, K. (2013). How do simple positive activities increase well-being? Current Directions in Psychological Science, 22(1), 57-62. https://doi.org/10.1177/0963721412469809.

Lyubomirsky, S., Sheldon, K. M., \& Schkade, D. (2005). Pursuing happiness: The architecture of sustainable change. Review of General Psychology, 9(2), 111-131. https://doi.org/10.1037/1089-2680.9.2.111.

MacBeth, A., \& Gumley, A. (2012). Exploring compassion: a meta-analysis of the association between selfcompassion and psychopathology. [Review]. Clinical Psychology Review, 32(6), 545-552. https://doi. org/10.1016/j.cpr.2012.06.003.

McCullough, M. E., Emmons, R. A., \& Tsang, J. A. (2002). The grateful disposition: A conceptual and empirical topography. Journal of Personality and Social Psychology, 82(1), 112-127.

McCullough, M. E., Tsang, J.-A., \& Emmons, R. A. (2004). Gratitude in intermediate affective terrain: links of grateful moods to individual differences and daily emotional experience. Journal of Personality and Social Psychology, 86(2), 295.

Millstein, R. A., Celano, C. M., Beale, E. E., Beach, S. R., Suarez, L., Belcher, A. M., et al. (2016). The effects of optimism and gratitude on adherence, functioning and mental health following an acute coronary syndrome. General Hospital Psychiatry, 43, 17-22.

Nelson, S. K., Bohlmeijer, E., \& Schotanus-Dijkstra, M. (Submitted). Other-focused kindness versus selffocused kindness among those at risk for mental disorders: results of a randomized controlled trial.

Nelson, S. K., Layous, K., Cole, S. W., \& Lyubomirsky, S. (2016). Do unto others or treat yourself? The effects of prosocial and self-focused behavior on psychological flourishing. [Article]. Emotion, 16(6), 850-861. https://doi.org/10.1037/emo0000178. 
Radloff, L. S. (1977). The CES-D scale: A self-report depression scale for research in the general population. Applied Psychological Measurement, 1(3), 385-401.

Rosenberg, E. L. (1998). Levels of analysis and the organization of affect. Review of General Psychology, 2(3), 247-270.

Santor, D. A., Zuroff, D. C., Ramsay, J., Cervantes, P., \& Palacios, J. (1995). Examining scale discriminability in the BDI and CES-D as a function of depressive severity. Psychological Assessment, 7(2), 131.

Schotanus-Dijkstra, M., Drossaert, C. H. C., \& Bohlmeijer, E. T. (2019a). People's motives to participate in a positive psychology intervention with email support and who might benefit most? [Journal article]. International Journal of Applied Positive Psychology. https://doi.org/10.1007/s41042-018-00013-0.

Schotanus-Dijkstra, M., Keyes, C. L. M., de Graaf, R., \& Ten Have, M. (2019b). Recovery from mood and anxiety disorders: The influence of positive mental health. Journal of Affective Disorders, 252, 107-113. https://doi.org/10.1016/j.jad.2019.04.051.

Schotanus-Dijkstra, M., Pieterse, M. E., Drossaert, C. H. C., Westerhof, G. J., de Graaf, R., ten Have, M., et al. (2016). What factors are associated with flourishing? Results from a large representative national sample. [Journal article]. Journal of Happiness Studies, 17(4), 1351-1370. https://doi.org/10.1007/ s10902-015-9647-3.

Schotanus-Dijkstra, M., ten Have, M., Lamers, S., de Graaf, R., \& Bohlmeijer, E. T. (2017). The longitudinal relationship between flourishing mental health and incident mood, anxiety and substance use disorders. European Journal of Public Health, 27(3), 563-568.

Sheldon, K. M., \& Lyubomirsky, S. (2012). The challenge of staying happier: Testing the hedonic adaptation prevention model. Personality and Social Psychology Bulletin, 38(5), 670-680. https://doi. org/10.1177/0146167212436400.

Shin, L. J., \& Lyubomirsky, S. (2017). Increasing well-being in independent and interdependent cultures. Scientific advances in positive psychology, pp. 11-36.

Singer, J. D., \& Willett, J. B. (2003). Applied longitudinal data analysis: Modeling change and event occurrence. Oxford, United Kingdom: Oxford University Press.

Sirois, F. M., \& Wood, A. M. (2017). Gratitude uniquely predicts lower depression in chronic illness populations: A longitudinal study of inflammatory bowel disease and arthritis. Health Psychology, 36(2), 122.

Spitzer, R. L., Kroenke, K., Williams, J. B., \& Löwe, B. (2006). A brief measure for assessing generalized anxiety disorder: The GAD-7. Archives of Internal Medicine, 166(10), 1092-1097.

Watkins, P. C., Uhder, J., \& Pichinevskiy, S. (2015). Grateful recounting enhances subjective well-being: the importance of grateful processing. The Journal of Positive Psychology, 10(2), 91-98.

Watkins, P. C., Woodward, K., Stone, T., \& Kolts, R. L. (2003). Gratitude and happiness: Development of a measure of gratitude, and relationships with subjective well-being. Social Behavior and Personality: an international journal, 31(5), 431-451.

Westerhof, G. J., \& Keyes, C. L. (2010). Mental illness and mental health: The two continua model across the lifespan. Journal of Adult Development, 17(2), 110-119. https://doi.org/10.1007/s1080 4-009-9082-y.

Whiteford, H. A., Degenhardt, L., Rehm, J., Baxter, A. J., Ferrari, A. J., \& Erskine, H. E. (2013). Global burden of disease attributable to mental and substance use disorders: Findings from the global burden of disease study 2010. Lancet. https://doi.org/10.1016/s0140-6736(13)61611-6.

Wood, A. M., Joseph, S., \& Linley, P. A. (2007). Coping style as a psychological resource for grateful people. Journal of social and clinical psychology, 26, 1076-1093.

Wood, A. M., Froh, J. J., \& Geraghty, A. W. A. (2010). Gratitude and well-being: a review and theoretical integration. Clinical Psychology Review. https://doi.org/10.1016/j.cpr.2010.03.005.

Wood, A. M., \& Joseph, S. (2010). The absence of positive psychological (eudemonic) well-being as a risk factor for depression: a ten year cohort study. Journal of Affective Disorders, 122(3), 213-217. https:// doi.org/10.1016/j.jad.2009.06.032.

Wood, A. M., Joseph, S., \& Maltby, J. (2009). Gratitude predicts psychological well-being above the Big Five facets. Personality and Individual Differences, 46(4), 443-447.

Publisher's Note Springer Nature remains neutral with regard to jurisdictional claims in published maps and institutional affiliations. 